\title{
Role of stratospheric air in a severe weather event: Analysis of potential vorticity and total ozone
}

\author{
Melissa A. Goering and William A. Gallus Jr. \\ Department of Geological and Atmospheric Sciences, Iowa State University, Ames, Iowa \\ Mark A. Olsen and John L. Stanford \\ Department of Physics and Astronomy, Iowa State University, Ames, Iowa
}

\begin{abstract}
The role of dry stratospheric air descending to low and middle tropospheric levels in a severe weather outbreak in the midwestern United States is examined using NCEP Eta model output, Rapid Update Cycle (RUC) analyses, and Earth probe Total Ozone Mapping Spectrometer (EP/TOMS) total ozone data. While stratospheric air was not found to play a direct role in the convection, backward trajectories show stratospheric air descended to $800 \mathrm{hPa}$ just west of the convection. Damaging surface winds not associated with thunderstorms also occurred in the region of greatest stratospheric descent. Small-scale features in the high-resolution total ozone data compare favorably with geopotential heights and potential vorticity fields, supporting the notion that stratospheric air descended to near the surface. A detailed vertical structure in the potential vorticity appears to be captured by small-scale total ozone variations. The capability of the total ozone to identify mesoscale features assists model verification. The total ozone data suggest biases in the RUC analysis and Eta forecast of this event. The total ozone is also useful in determining whether potential vorticity is of stratospheric origin or is diabatically generated in the troposphere.
\end{abstract}

\section{Introduction}

Stratospheric intrusions into the troposphere, sometimes called tropopause folds (descending as low as $\sim 800 \mathrm{hPa}$ ), have been analyzed by using potential vorticity (PV) for over half a century [Kleinschmidt, 1951; Reed and Sanders, 1953; Reed, 1955; Reed and Danielsen, 1959; Danielsen, 1968; Shapiro and Keyser, 1990; Uccellini et al., 1985]. High values of PV occur in the stratosphere primarily because of its high static stability, as seen by Ertel's [1942] relation, $\mathrm{PV}=-g \eta \partial \theta / \partial p$, where $\eta$ is absolute isentropic vorticity, $g$ is gravitational constant, $\partial \theta / \partial p$ is static stability, and $\theta$ is potential temperature. For adiabatic and frictionless motion, air parcels conserve PV values, usually measured in potential vorticity units (PVU), where $1 \mathrm{PVU}=$ $10^{-6} \mathrm{~m}^{2} \mathrm{~K} \mathrm{~kg}^{-1} \mathrm{~s}^{-1}$. The dynamic tropopause has been defined with PV values ranging from 1.0 PVU [Bithell et al., 2000; Hoskins et al., 1985] to 3.5 PVU [Hoerling et al., 1993; Spaete et al., 1994]. In the present study, stratospheric air will be defined using PV values $\geq 2$ PVU.

Tropopause folds have been examined in relation to severe weather not directly associated with thunderstorms. Browning and Reynolds [1994] studied a tropopause fold event over the United Kingdom which caused damaging surface winds (gusting $36 \mathrm{~ms}^{-1}$ ). The damaging winds were attributed to the downward momentum associated with the tropopause fold. Knowledge of how stratospheric air may also affect severe thunderstorms is important; the convective environment may be enhanced when drier stratospheric air descends to middle levels, because potential instability may result. During severe weather events over the central United States, dry tropo-

Copyright 2001 by the American Geophysical Union.

Paper number 2000JD900651.

0148-0227/01/2000JD900651\$09.00 spheric air is often observed originating in the southwest deserts and Mexican plateau [Carlson et al, 1980]. This air overrides low moist air, creating an inversion that can delay or prevent the release of latent instability, and enhancing potential instability [Palmen and Newton, 1969]. A similar result could occur if dry stratospheric air descended to relatively low altitudes [Griffiths et al., 2000]. In the Koch and Kocin's [1991] study, line convection developed due to descending midtropospheric air. However, they felt that stratospheric air may have been entrained. The role of stratospheric air in severe weather both apart from and within thunderstorms needs to be investigated for potential use in predicting damaging winds and enhanced atmospheric instability.

Folds are not only associated with high values of PV intruding down to normally tropospheric altitudes but also ozone. As a result, total column ozone (or total ozone) can show dramatic changes near a fold. Olsen et al. [2000], for instance, have demonstrated a $30 \%$ increase in total ozone across a fold. Smaller variations in total ozone may be due to other factors such as changes in ozone mixing ratio at higher stratospheric levels. The total ozone relationship can be expressed as [ $\mathrm{Zi}$ emke and Stanford, 1994]

$$
\Omega \propto \int \rho(z) \chi(z) d z,
$$

where $\Omega$ is total column ozone, $\propto$ is proportionality expression, $\rho$ is density of air, $\chi$ is ozone mixing ratio, and $z$ is geometric height. Total column ozone is generally expressed in Dobson units (DU), where $1 \mathrm{DU}=10^{-5} \mathrm{~m}$ at standard atmospheric temperature and pressure. From the above equation, ozone of a given mixing ratio at lower altitudes will contribute more to the total ozone, because of greater air density at lower heights.

Danielsen [1968], Vaughan and Begun [1989], Allaart et al. 
[1993], Langford et al. [1996], and Ravetta et al. [1999] provide evidence for a correlation between ozone and PV. Both quantities are approximately conserved on synoptic timescales [Davis et al., 1999] (dissipation rates will be discussed in a subsequent paper). Recently, Olsen et al. [2000] compared high horizontal resolution $(\sim 40 \mathrm{~km})$ total column ozone with PV from a mesoscale model analysis of similar resolution. Finescale structure in the model analysis agreed well with total column ozone. Although the correlation between ozone and PV has been well established (such that the European Center for Medium-Range Weather Forecasting is testing methods of assimilation of ozone data available in near real time), the usefulness of the high-resolution EP/TOMS total ozone as a mesoscale analysis or forecasting tool requires further investigation.

The purpose of this paper is to examine a severe weather event associated with an intense cyclone accompanied by a pronounced stratospheric intrusion. Backward trajectories from a mesoscale model and high-resolution satellite-derived total column ozone observations are used to analyze the role played by stratospheric air. The data are described in section 2 . The role of descending dry stratospheric air in severe weather is examined in section 3 using backward trajectories. Comparisons of high-resolution total column ozone data with model analyses are presented in section 4 . The final section gives a summary of results and suggested uses of total column ozone data for weather prediction and model verification.

\section{Data and Methodology}

\subsection{Model Output}

The analyses used to show the development of the cyclone are from the National Center for Environmental Prediction (NCEP) RUC model provided by the University Corporation for Atmospheric Research UNIDATA program. The RUC data are interpolated vertically from 40 vertical levels (a hybrid of sigma and theta) to 19 evenly spaced isobaric levels between $1000 \mathrm{hPa}$ and $100 \mathrm{hPa}$ and interpolated horizontally to an 80 $\mathrm{km}$ resolution grid. The RUC analyses combine rawindsonde, aircraft, profiler, and surface observations. An advantage of the RUC model is that the vertical coordinate is isentropic in the upper troposphere and lower stratosphere, providing relatively fine vertical resolution, and the model uses highfrequency data assimilation [Benjamin et al., 1994].

The RUC model analyses are compared with output from a workstation version of the NCEP Eta model [e.g., Janjic, 1994] run with $40 \mathrm{~km}$ horizontal resolution, 45 vertical levels, and a model top of $25 \mathrm{hPa}$. Lateral boundary conditions and initial fields for the Eta model were supplied from the $80 \mathrm{~km}$ RUC analyses. Therefore comparisons between the Eta and the RUC models are not completely independent. To determine backward trajectories, the Eta model was initialized with the RUC analyses at 1200 UTC on April 7 and 0000 UTC and 1200 UTC on April 8, 1999, and integrated for 12 hours in all three runs.

\subsection{Total Column Ozone}

The total ozone data used in this study are from the polar orbiting Earth probe Total Ozone Mapping Spectrometer (EP/ TOMS) at an altitude of $750 \mathrm{~km}$. The EP/TOMS scans from right to left in $3^{\circ}$ steps, with a total of 35 measurements taken before beginning a new scan line. Each scan line is perpendicular to the direction of satellite motion. EP/TOMS total ozone is derived by comparing measured radiances with theoretical radiances [McPeters et al., 1998]. The total ozone used in the present study is from EP/TOMS along-track, nongridded, Level 2 data provided by the NASA Goddard Space Flight Center. The horizontal resolution is $\sim 40 \mathrm{~km}$ for the nadir observations, degrading for increasing scan angles. Total ozone data from an orbit crossing the equator at 1750 UTC will be compared with heights, winds, and PV from the 1800 UTC RUC analysis.

\section{Meteorological Analysis}

\subsection{Surface and 500 hPa Evolution}

On April 8, 1999, severe thunderstorms developed across Nebraska, Iowa, and Missouri producing several tornadoes, $>4$ cm diameter hail, and winds $>30 \mathrm{~ms}^{-1}$ [National Climatic Data Center (NCDC), 1999]. Although our case does not meet the definition of "explosive" cyclogenesis ( $24 \mathrm{hPa}$ drop in 24 hours) noted by Sanders and Gyakum [1980], the deepening of the cyclone is still considerable, with a drop of $12 \mathrm{hPa}$ in 18 hours. The surface and $500 \mathrm{hPa}$ evolution during the morning of April 8, 1999, can be seen in Plate 1.

On the evening of April 7, surface low pressure was developing over the Rocky Mountains as the $500 \mathrm{hPa}$ trough deepened there (not shown). From 0000 to 1200 UTC the surface low pressure intensified by $8 \mathrm{hPa}$ as the $500 \mathrm{hPa}$ heights began to fall in the Southern Plains, indicating strong dynamic forcing. By 1200 UTC (Plate 1a) the surface low with a central pressure of $990 \mathrm{hPa}$ was located over southwest Nebraska. Also at this time, a dry line was evident from western Kansas, extending southward through Oklahoma and Texas (pressure trough in Plate 1a). The warm front can be seen by the kink in the isobars (Plate 1a), stretching along the Nebraska-Kansas border and eastward through northern Missouri. A strong vorticity maximum coincided with lower heights at $500 \mathrm{hPa}$ (Plate 1b).

At 1800 UTC the surface low reached a central pressure of $986 \mathrm{hPa}$ (Plate 1c) in central Nebraska. The tightly wrapped circulation, seen in an infrared (IR) satellite image (Figure 1a) is typical of a LC2 baroclinic wave described by Thorncroft et al. [1993] in which the system wraps up cyclonically during its life cycle. At $500 \mathrm{hPa}$, a closed low was centered over the surface low (Plate 1d), and the closed circulation extended as high as $200 \mathrm{hPa}$ (not shown). A closer view of the developing convection in Nebraska and Iowa is shown in Figure 1b.

The surface low weakened from 1800 UTC on April 8, 1999, to 0600 UTC on April 9, 1999, and moved eastward (not shown). Severe weather continued to develop as it moved to the east, producing an F4 tornado in Ohio which killed four people and caused 80 million dollars in damage.

\subsection{Isentropic Analyses of $P V$ and Pressure}

The PV evolution in the 315-320 and 320-325 K isentropic layers, from the RUC analysis (with corresponding pressures on the 315 and $320 \mathrm{~K}$ isentropic surfaces) is presented from 1200 UTC (Figure 2) to 1800 UTC (Figure 3). In the 315-320 $\mathrm{K}$ layer at $1200 \mathrm{UTC}$ (Figure 2a), stratospheric air in west central Montana extends southward over Colorado in a streamer-like feature [Appenzeller and Davies, 1992]. The 2 PVU contour extends down to $480 \mathrm{hPa}$ in southeast Colorado (Figures $2 \mathrm{a}$ and $2 \mathrm{~b}$ ). An advantage of using isentropic analyses is that the vertical motion may be easily implied from the wind field overlaid on the pressures. If the local rate of change of the 

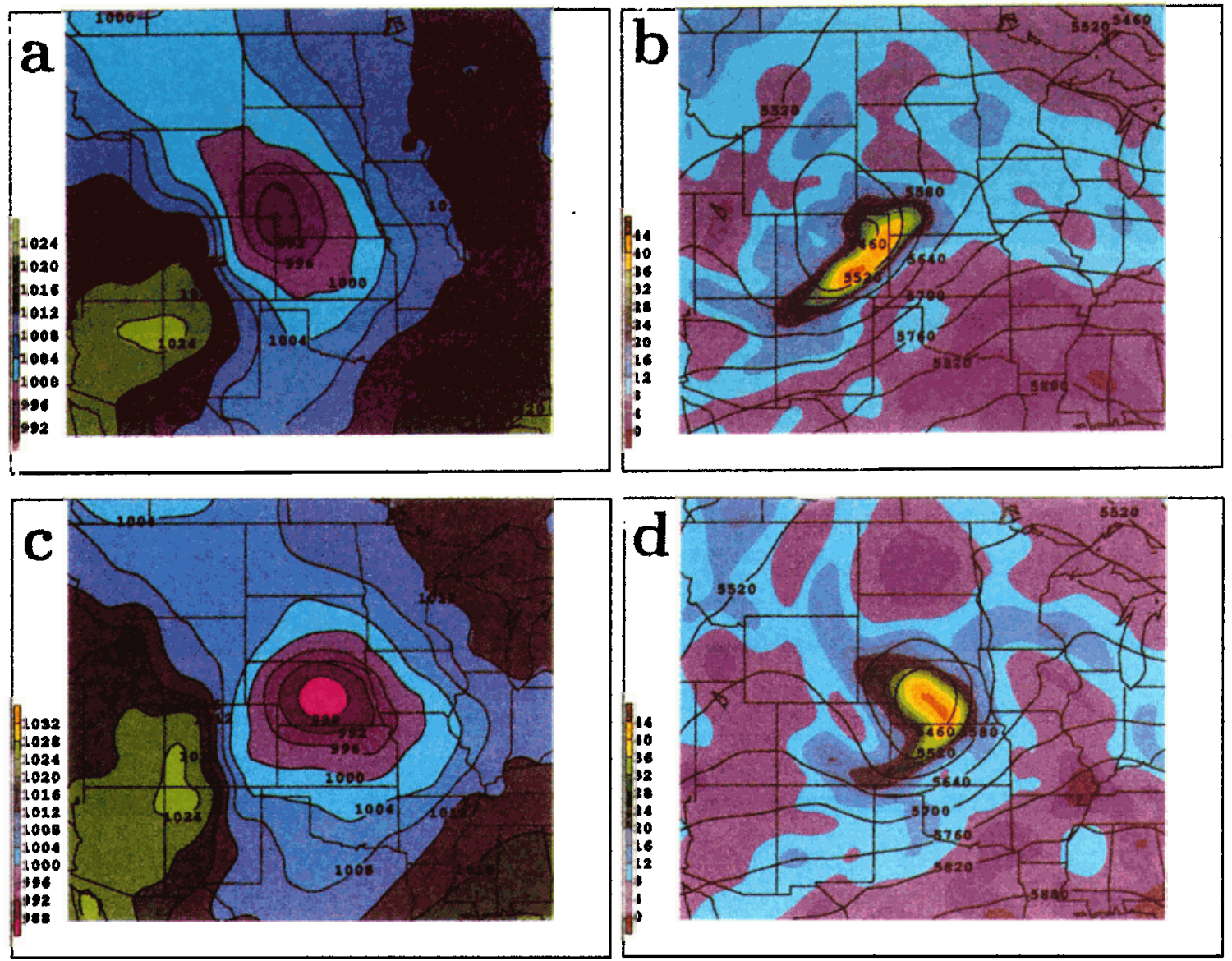

Plate 1. RUC analyses for (a, b) 1200 UTC and (c, d) 1800 UTC on April 8, 1999. Sea level pressure (color shading) is shown in Plates $1 \mathrm{a}$ and $1 \mathrm{c}$ with contour intervals of $4 \mathrm{hPa}$. Geopotential heights (solid) with absolute vorticity (color shading) at $500 \mathrm{hPa}$ are shown in Plates $1 \mathrm{~b}$ and $1 \mathrm{~d}$. Contour intervals of $60 \mathrm{~m}$ are used for heights and $4 \times 10^{-5} \mathrm{~s}^{-1}$ for vorticity.

a

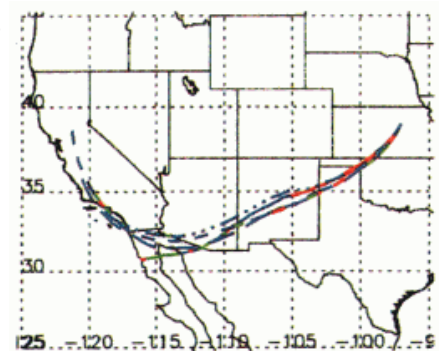

C

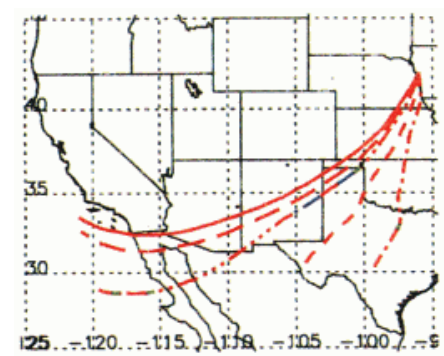

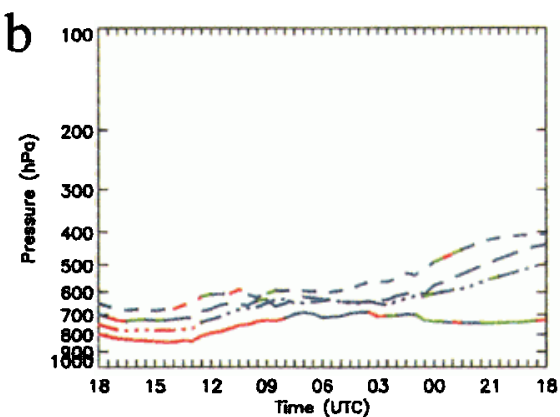

d

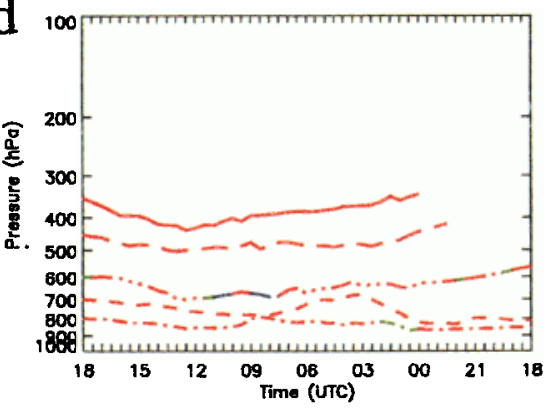

Plate 2. Backward trajectories over a 24 hour period ending at 1800 UTC on April 8, 1999. Horizontal paths are shown for points at (a) $39^{\circ} \mathrm{N}, 97^{\circ} \mathrm{W}$ and (c) $42^{\circ} \mathrm{N}, 96^{\circ} \mathrm{W}$. Time-pressure cross sections for Plate $2 \mathrm{a}$ shown in Plate $2 b$, and Plate $2 \mathrm{c}$ shown in Plate $2 \mathrm{~d}$. PV values $<1.5$ PVU are shown in red, between 1.5 and 2.0 PVU are shown in green, and $\geq 2.0$ PVU are shown in blue. Time evolves from right (April 7) to left (April 8). 


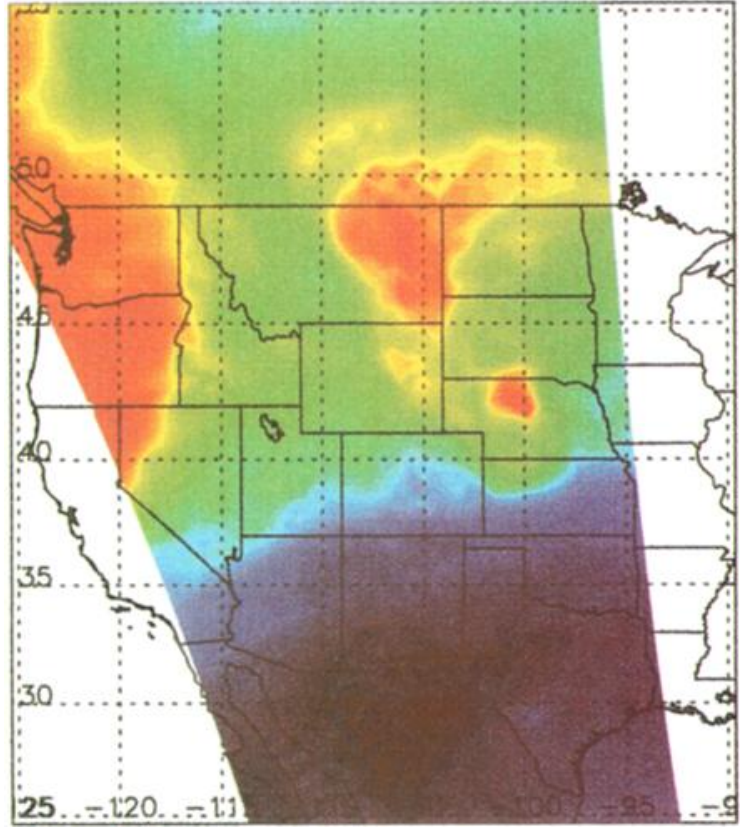

Total Column Ozone (DU)

244.

291.

337.

384.

430. 0 .

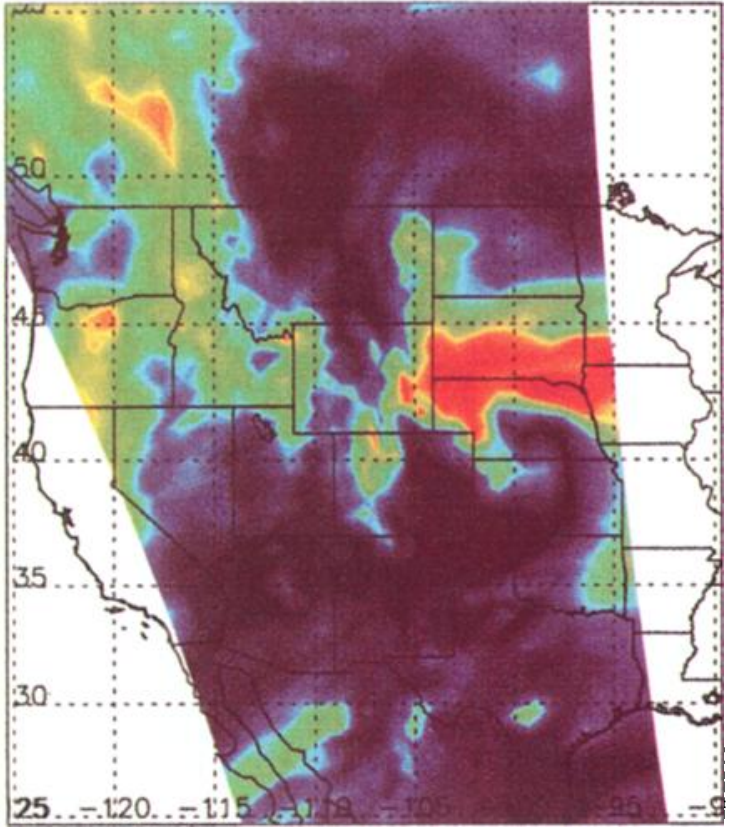

Reflectivity (\%)

Plate 3. Earth probe Total Ozone Mapping Spectrometer (EP/TOMS) measurements on April 8, 1999, of (a) total column ozone and (b) reflectivity measured at $360.4 \mathrm{~nm}$. The local equator crossing time is 1750 UTC. Total ozone is measured in Dobson units (DU $=10^{-5} \mathrm{~m}$ at STP) and reflectivity as a percentage of incoming solar radiation. Contour values indicated on color bars.

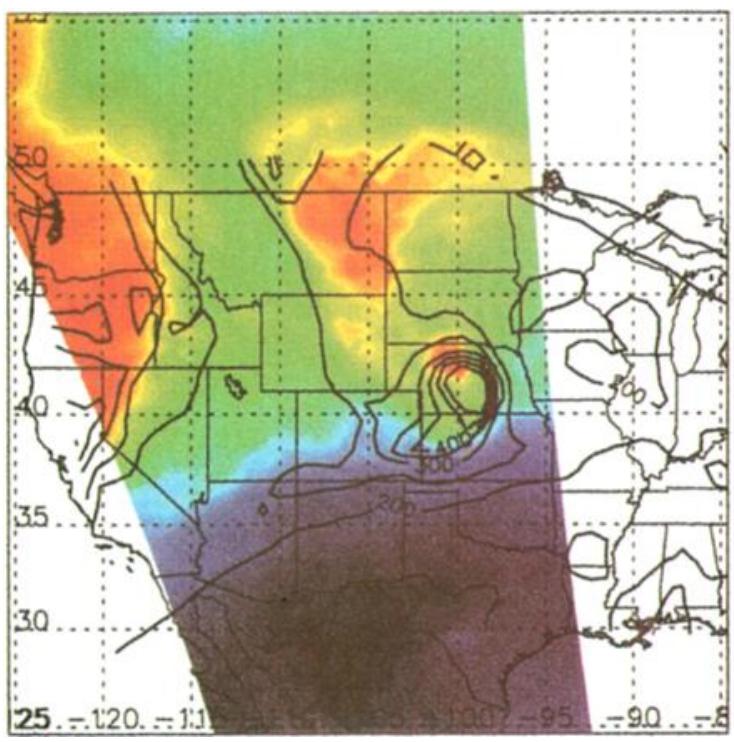

Total Column Ozone (DU)

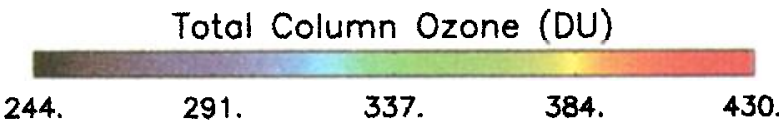

Plate 4. EP/TOMS total ozone (color shading) overlaid with 1800 UTC RUC analysis (contour lines) of tropopause pressure on April 8, 1999. Total ozone measured in DU with contour values indicated on color bar. Pressures contoured with $50 \mathrm{hPa}$ intervals. pressure is small, and adiabatic and frictionless conditions are present, ascent occurs when flow is directed from high to low pressure. This can be seen in north central Kansas (Figures $2 b$ and 2d). In the 320-325 K layer (Figure 2c) and higher (not shown) the larger PV values indicate more stratospheric air encompassing the northern United States with pressures $<300$ hPa.

By 1800 UTC the 2 PVU contour in the central United States in the 315-320 K layer (Figure 3a) is no longer connected with the region in Montana. This may be due to the 2 PVU contour thinning out in a scale-contraction process. Lamarque and Hess [1994] found that as a folded region thins with time, there is also an erosion of PV. PV structures are reduced to scales that may be unresolvable by model grids [Bithell et al., 1999]. The 320-325 K layer shows a pool of stratospheric air residing over central Nebraska with PV $>6$ PVU (Figure 3c). The maximum PV is part of the southern extent of a streamer from Montana and Canada which has rolled up into a spiral-like form. Similar features can also be seen in the work of Lamarque and Hess [1994]. Appenzeller and Davies [1992] and Appenzeller et al. [1996] observed stratospheric intrusions that developed into slender and elongated streamers of PV. A portion of the PV would eventually split from the main reservoir and wrap up cyclonically in a pattern similar to that in Figure 3c. In both the $325-330 \mathrm{~K}$ and the $330-335 \mathrm{~K}$ isentropic layers (not shown) a tight gradient in PV exists from Canada through Montana, wrapping cyclonically through Kansas and Nebraska. Again, cross-isobaric flow implying ascent can be seen over Kansas, Nebraska, and Iowa in 
a

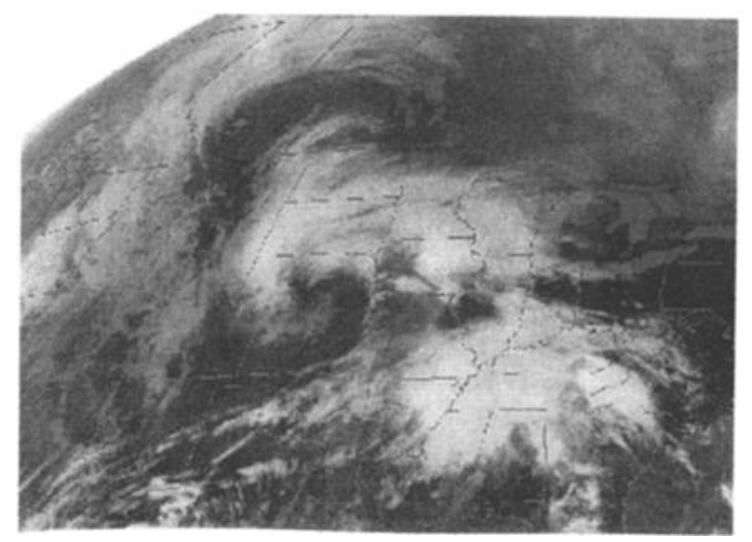

b

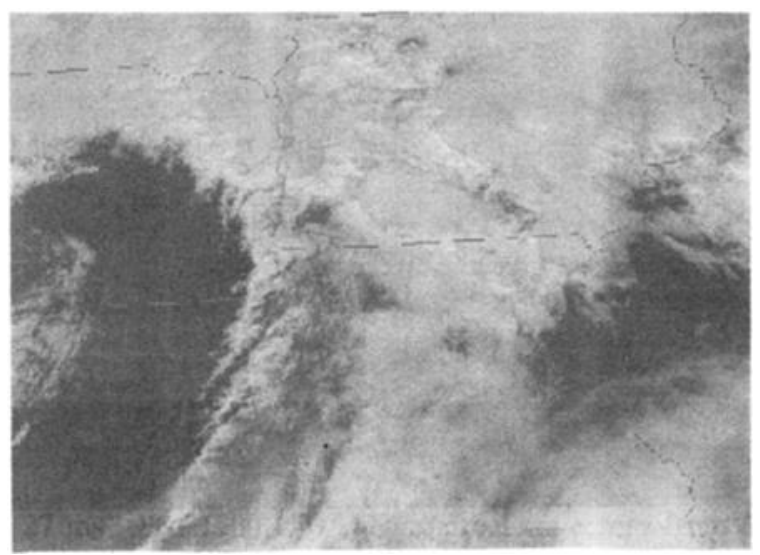

Figure 1. GOES-8 (a) infrared (IR) image of United States and (b) visible (VIS) image of Nebraska-Iowa border at 1815 UTC on April 8, 1999.

Figures $3 \mathrm{~b}$ and $3 \mathrm{~d}$. Downward motion is implied over most of Colorado behind and toward the rear of the PV maximum in various isentropic layers. These implied vertical motions are supported by detailed parcel trajectories, which will be discussed in the following section.

\subsection{Parcel Trajectories}

Full three-dimensional winds from the $40 \mathrm{~km}$ Eta simulations were used to determine parcel trajectories. These compared favorably with isentropic trajectories. Although many trajectories were examined, only a few are shown here. The trajectories chosen provide supporting evidence of stratospheric descent in relation to the total ozone discussed in section 4 .

3.3.1. Severe weather not associated with thunderstorms. The role of stratospheric air in severe weather not associated with thunderstorms is examined in Plates $2 a$ and $2 b$ by determining the trajectories of parcels reaching the region where damaging winds occurred. Downward momentum of stratospheric air in the tropopause fold may have been associated with severe weather across Kansas and the Texas-Oklahoma panhandle region. Parcels reaching northeast Kansas at 1800 UTC (Plates 2a and 2b) had followed a path across south central Kansas where damaging winds were reported (gusts over $27 \mathrm{~ms}^{-1}$ ) at 1500 UTC. The parcel trajectory from 700
$\mathrm{hPa}$ had descended to $729 \mathrm{hPa}$ with PV exceeding $2 \mathrm{PVU}$ over the region reporting damaging winds at 1500 UTC. Stratospheric origin of air is also indicated in the trajectories arriving at $750 \mathrm{hPa}$ and, in some cases, as low as $800 \mathrm{hPa}$ (not shown). However, the high PV values were diluted (below 2 PVU) in the six hours prior to 1800 UTC.

Similar results were seen in parcel trajectories from the northern Texas and Oklahoma panhandles. Winds reportedly caused damage at $1600 \mathrm{UTC}$ in these regions, where stratospheric air had descended to $600 \mathrm{hPa}$.

On the basis of examination of backward trajectories, stratospheric air may have had a direct role in producing damaging winds. Clear skies around these times allowed for strong surface heating which in turn enabled boundary layer growth. The development of the convective boundary layer facilitated mixing of the rapidly moving stratospheric air downward to the surface. These findings are similar to Browning and Reynolds [1994].

3.3.2. Severe thunderstorms. In examining the role of stratospheric air in and near severe thunderstorms, we initially believed that dry stratospheric air was overrunning the lowlevel moist air, creating potential instability as described by Griffiths et al. [2000]. However, detailed PV analyses along parcel trajectories revealed that stratospheric air descended $\sim 150 \mathrm{~km}$ to the west of the convection. Dry air overrunning the low-level moist air was found to originate both at high levels in the troposphere and at lower levels over the southwestern deserts and Mexican plateau. This combination enhanced potential instability. The trajectories associated with regions of convection (Figure 1b) near Norfolk (OFK) and Omaha (OMA), Nebraska, and Sioux City (SUX), Iowa, were examined.

The trajectories at SUX $\left(42^{\circ} \mathrm{N}, 96^{\circ} \mathrm{W}\right)$ are shown in Plates $2 \mathrm{c}$ and $2 \mathrm{~d}$ (the other sites had similar results). Parcels arriving at $600 \mathrm{hPa}$ at $1800 \mathrm{UTC}$ had PV values 24 hours earlier of $\sim 1.5$ PVU, which, although below our threshold for the dynamic tropopause, would be considered stratospheric in some studies, and implies an origin near the tropopause. Although the air originating at $1800 \mathrm{UTC}$ on April 7 was at $550 \mathrm{hPa}$, a low tropopause existed in the region at that time due to a deep stratospheric intrusion. However, the thermodynamic tropopause (temperature lapse rate $<2^{\circ} \mathrm{C} \mathrm{km}^{-1}$ for a depth of $2 \mathrm{~km}$ [WMO, 1986]) was around $400 \mathrm{hPa}$ for this case. The trajectory arriving at $600 \mathrm{hPa}$ showed similarities to those from the other sites experiencing convection (Figure 1b). Between 0800 UTC and 1100 UTC the average PV value briefly exceeded 2 PVU. This enhanced value may have been due to diabatic effects since parcels were ascending and relative humidity (RH) values were increasing from 40 to $70 \%$. Surface observations during this time showed overcast skies, and a 1200 UTC satellite image showed a large cloud shield. The parcel followed the edge of the cloud shield, and this may explain the initially low RH values.

Stratospheric air was not found to play a direct role in the convection at SUX, OMA, and OFK. However, trajectory analyses do contain some error, and the nearness of the stratospheric air to the convection prevents its influence from being categorically denied. As in the work of Koch and Kocin [1991], some of the nearby stratospheric air may have been entrained into the convective region. Bithell et al. [2000] investigated the sensitivity of trajectories and found that errors could be as large as $1000 \mathrm{~km}$ per day due to errors in the winds used for advection. Although they used a coarser resolution $(\sim 100 \mathrm{~km})$ 

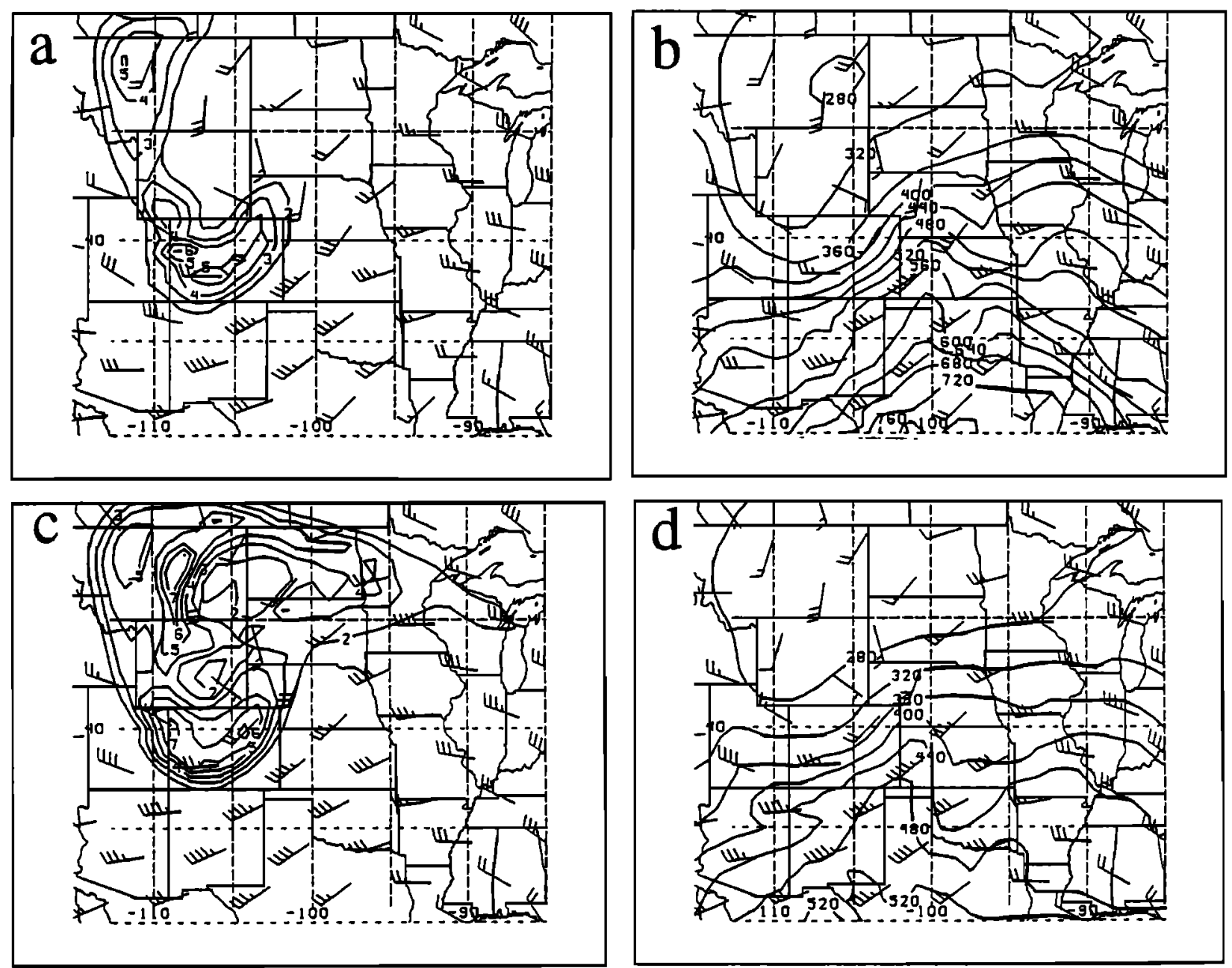

Figure 2. RUC analyses at 1200 UTC on April 8, 1999, of potential vorticity (with 1 PVU contour interval) in the (a) 315-320 K and (c) 320-325 K isentropic layers, and pressure (with $40 \mathrm{hPa}$ contour interval) on the (b) $315 \mathrm{~K}$ and (d) $320 \mathrm{~K}$ isentropic surface. Winds are overlaid on all maps using standard convention (one full barb is $5 \mathrm{~ms}^{-1}$ ).

than the present study, probably accounting for the larger potential errors, it is possible that stratospheric air descended somewhat closer to the convection than our analyses indicate.

\section{Total Ozone Comparison}

The total ozone data for a section of one orbit can be seen in Plate 3a. The total ozone clearly shows a streamer-like form with the center wrapping up in central Nebraska comparable to the PV in Figure 3c. The reflectivity, measured by EP/TOMS at $360.4 \mathrm{~nm}$, is the percentage of solar radiation that is not absorbed or transmitted (Plate $3 b$ ). The brighter features represent cloud-covered regions with higher percentages of reflectivity. Thus brighter reflectivity indicates higher and thicker cloud cover. When there is cloud cover, the TOMS algorithm adjusts total ozone values using cloud heights based on a climatological data set from the International Satellite Cloud Climatology Project [Hsu et al., 1997]. Although the TOMS algorithm can have errors in adjusting the total ozone for anomalous cloud heights with strong thunderstorm anvils [ $\mathrm{Ol}-$ sen et al., 2000], errors in general should not exceed $2 \%$ [McPeters et al., 1998]. When larger errors occur, the ozone values are anticorrelated with reflectivity. Such an anticorrelation is not apparent in Plate 3. In addition, cloud heights in this region, implied from RUC soundings, were fairly close to assumed climatological values near $400 \mathrm{hPa}$.

A comparison of the reflectivity data and the IR satellite image (Figure 1a) shows good agreement. Regions of low reflectivity match up fairly well with dry descending air that was shown earlier in the trajectories (Plates $2 \mathrm{a}$ and $2 \mathrm{~b}$ ). The dry stratospheric air descending within this region matches well with the band of higher total ozone. It can be seen that the highest values of total ozone in central Nebraska match the spiral feature of low reflectivity associated with the descending dry air. It should be noted that neither the reflectivity nor the total ozone data cover the easternmost portion of the cyclone due to the track of the satellite; however, this region is outside the focus of this paper.

\subsection{Total Ozone and Geopotential Height}

A good correlation has been found previously between total ozone and upper troposphere geopotential heights on both the synoptic scale [e.g., Stanford and Ziemke 1996, and references therein] and the mesoscale [Olsen et al., 2000]. Olsen et al. 

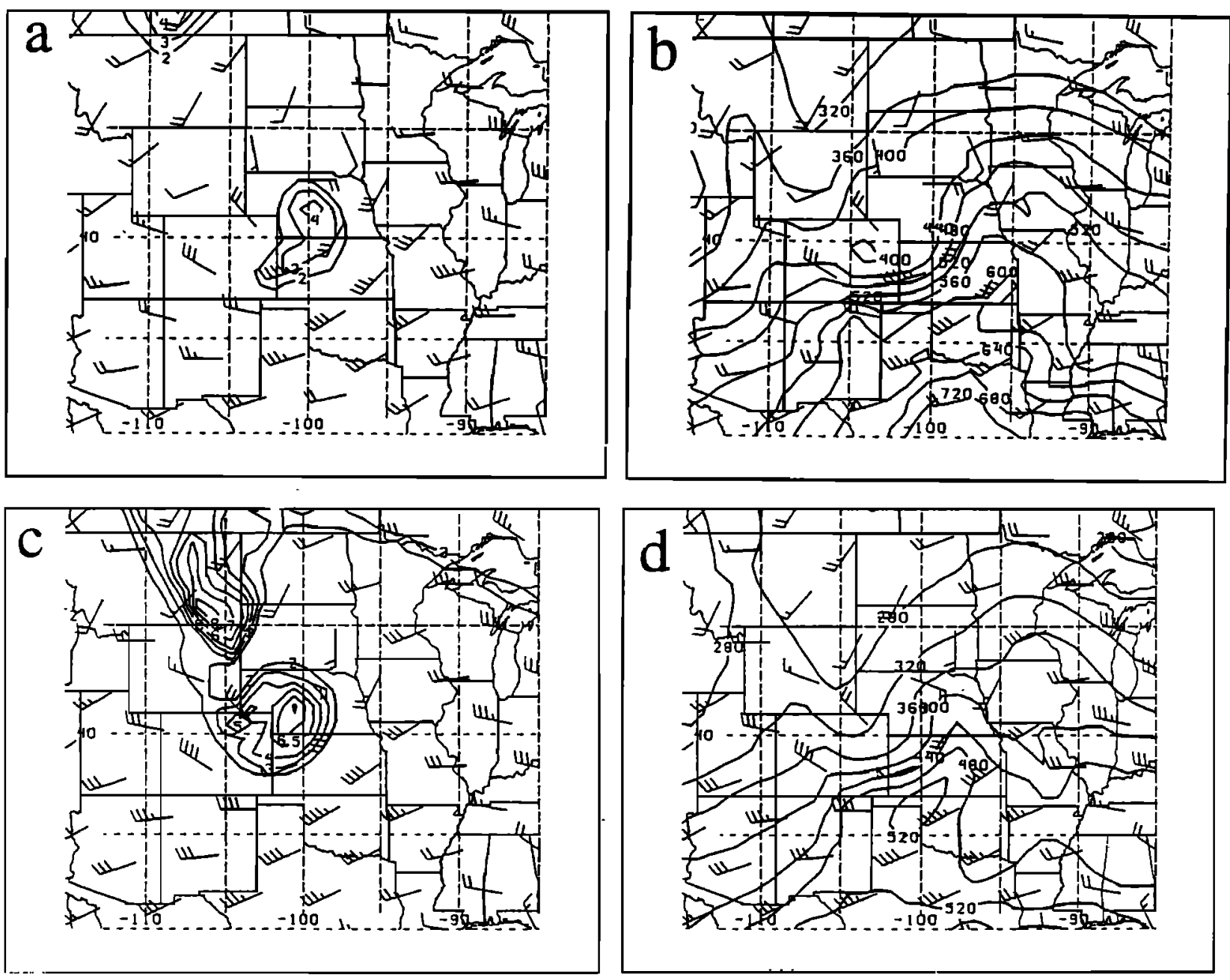

Figure 3. As in Figure 2 except at 1800 UTC.

found in a study of another intense Midwest cyclone that heights below $600 \mathrm{hPa}$ did not correlate as well because the fold in that case did not extend below $600 \mathrm{hPa}$. Since the trajectory analyses show that parcels of stratospheric origin reached pressures as low as $800 \mathrm{hPa}$ in the present case, agreement might be expected between the high total ozone and the geopotential heights through much of the troposphere near the fold region. Reasonably good agreement does occur in a limited area near the cyclone in the $400-800 \mathrm{hPa}$ layer where height contours roughly parallel the ozone contours (not shown), but the ozone data strongly suggest a southward bias in the RUC analysis (which is influenced by previous RUC forecasts) of the cyclone.

The highest total ozone is displaced $100-200 \mathrm{~km}$ northward from the lowest tropopause heights (highest tropopause pressures in Plate 4), and because this system did not tilt in the vertical, the ozone maximum is also north of the low-level cyclone position. Although the total ozone maximum may be due in part to dynamics in the upper atmosphere, sequential analyses and forecasts during the event suggest a small spatial error within the RUC and Eta model output. Throughout the day, successive RUC and Eta model runs slowly moved the track of the low pressure northward. In spite of the northward shift, however, the models did not precisely depict the location of the surface low pressure. The model's southward bias also caused problems in forecasting the regions at highest risk for severe weather. At 1300 UTC the Storm Prediction Center (SPC) forecasted a high risk of severe weather for eastern Missouri. By 2000 UTC the SPC high-risk region was moved northward to western and southern Iowa, in association with the model's northward shift in cyclone track. These results suggest the possibility of using total ozone as an additional source of information that could help forecasters note spatial model errors; analyses could be adjusted to show the true location of important meteorological features. The benefits of using the data in this way are currently limited by the polar orbiting configuration and a small time delay in data availability.

In addition to the spatial error in the RUC analysis, its relatively coarse resolution limits the vertical extent of the tropopause fold, as will be shown later in a comparison of the total ozone data with the higher-resolution Eta model forecasts.

\subsection{Vertical Cross Sections}

For the vertical cross sections to be discussed in this section, the PV field is linearly interpolated to the total ozone horizontal grid. All cross sections shown are taken from $30^{\circ} \mathrm{N}$ to $50^{\circ} \mathrm{N}$. 
4.2.1. Total ozone comparison with an $80 \mathrm{~km}$ RUC analysis. A vertical cross section from the RUC analysis is shown in Figure 4, corresponding to track e (Plate 5a). The 2 PVU contour identifying the tropopause fold reaches to $650 \mathrm{hPa}$. The darker solid line in Figure 4 is the total ozone for the same cross section with DU noted on the right-hand side of the figure. There are two main peaks in total ozone near the fold, centered near $41^{\circ} \mathrm{N}$ and $43.5^{\circ} \mathrm{N}$.

The rapid increase in total ozone from $36^{\circ} \mathrm{N}$ to $40^{\circ} \mathrm{N}$ can be understood from (1). Stratospheric air should contain relatively high values of both PV and ozone mixing ratio. If diffusion and mixing processes are unimportant, the PV contours in Figure 4 can be used to visualize contours of ozone mixing ratio. On this basis, (1) predicts that total column ozone should be expected to increase in a manner similar to that observed in Figure 4. Using PV as a surrogate for ozone, the peak between $39^{\circ} \mathrm{N}$ and $42^{\circ} \mathrm{N}$ seems to be due to the contribution of ozone from lower altitudes. An elevated pocket of ozone (PV) at 150 $\mathrm{hPa}$ may also be adding to the contribution of total ozone in this maximum.

The peak in total ozone at $43.5^{\circ} \mathrm{N}$ does not seem to be associated with an identifiable feature in the PV field. As will be seen in the next section, the disagreement appears to be due to inadequate horizontal resolution in our RUC analysis. The total ozone data capture finer-scale features than the coarse RUC analysis. We next compare the total ozone data with higher-resolution model output from an Eta model run.

4.2.2. Total ozone comparison with $40 \mathrm{~km}$ Eta model. Vertical cross sections from the Eta model 6 hour forecast valid at 1800 UTC are shown in Plates 5b-5e, corresponding to the tracks in Plate 5a. The forecast errors associated with the 6 hour forecast appear to be relatively small, as model output agrees reasonably well with the available observations. More detailed structures can be seen in the $40 \mathrm{~km}$ resolution Eta run compared to our RUC output. Examining cross-section b (Plate $5 \mathrm{~b}$ ), total ozone increases rapidly northward, by over $40 \%$ from $35^{\circ} \mathrm{N}$ to the first peak at $40^{\circ} \mathrm{N}$. The increase is due to high ozone values in the lower troposphere. The fold extends from $200 \mathrm{hPa}$ down to $800 \mathrm{hPa}$ at $33^{\circ} \mathrm{N}$. The peak at $40^{\circ} \mathrm{N}$ can be seen as a contribution of low-level ozone (using PV as a surrogate for ozone to a first approximation), and two pockets of higher-level ozone (at 300 and $150 \mathrm{hPa}$ ). Another total ozone peak at $42^{\circ} \mathrm{N}$ may be attributed to the ozone (PV), increasing at the higher levels $(100-200 \mathrm{hPa})$, as well as a pocket of ozone (PV) slightly above $300 \mathrm{hPa}$.

The low-level PV from $39^{\circ} \mathrm{N}$ to $45^{\circ} \mathrm{N}$ is not contributing to the two total ozone peaks. By examining the midlevel PV and total ozone, it can be seen that there is a decrease in both in this region. Recall from (1) that low-altitude ozone mixing ratio will contribute more to total ozone than higher-altitude ozone of the same magnitude. Therefore since the low-level PV does not correlate with the total ozone, it is probably generated by diabatic effects in the lower troposphere. Supporting evidence can be seen in the reflectivity data (Plate $3 b$ ) and the IR satellite image (Figure 1a), both of which indicate cloud cover in western Nebraska. In addition, the RH values were examined and found to exceed $80 \%$ (not shown). Thus it is probable that the high values of PV at these low altitudes are caused by diabatic (cloud condensation) effects.

In cross-section c, just west of the total ozone maximum (Plate 5c), fine-scale structure is evident in the lowermost portion of the fold from $34^{\circ} \mathrm{N}$ to $39^{\circ} \mathrm{N}$. The double-peak structure in total ozone around $40^{\circ} \mathrm{N}-42^{\circ} \mathrm{N}$ appears to be due to the contribution of enhanced ozone mixing ratios in stratospheric air in a multiple-fold structure. The primary fold in Plate $5 \mathrm{c}$ extends down to $750-800 \mathrm{hPa}$ near $35^{\circ} \mathrm{N}$. A secondary fold is seen near $500 \mathrm{hPa}$ and $41^{\circ} \mathrm{N}$. The enhanced PV at low altitudes near $41^{\circ} \mathrm{N}-44^{\circ} \mathrm{N}$ is thought to be diabatically generated in the troposphere. Examination of RH reveals that stratospheric air extends down to $500 \mathrm{hPa}$ here. The tropospheric generated PV has $\mathrm{RH}$ greater than $80 \%$, whereas at $500 \mathrm{hPa}$ and above, $\mathrm{RH}$ is low.

Interesting tube-like features extend from track b eastward to track d at $200 \mathrm{hPa}$ (around $42^{\circ} \mathrm{N}$ ). Another tube of PV can be seen slightly below $500 \mathrm{hPa}$ (around $37^{\circ} \mathrm{N}$ ), extending from track c eastward to track d. These "tubes" of PV have been discussed by several authors [Lamarque and Hess, 1994; Bithell et al., 1999; Olsen et al., 2000]. These tubes of PV correspond to localized ozone maxima that will enhance the total ozone [Olsen et al., 2000].

The cross section in track d (Plate 5d) slices through the total ozone maximum in central Nebraska. As in Plate 5c, the two peaks in total ozone near $40^{\circ} \mathrm{N}-42^{\circ} \mathrm{N}$ are attributed to the double-fold structure.

The last cross section (Plate 5e), taken just east of the highest total ozone, corresponds to the RUC cross section in Figure 4. The impact of higher-resolution model data is apparent when comparing Figure 4 with Plate 5e, with more vertical variability evident in the higher-resolution model output. (An additional sensitivity test using $22 \mathrm{~km}$ horizontal resolution found no appreciable changes in the intensity and vertical extent of the fold compared to the $40 \mathrm{~km}$ run, suggesting that resolutions of $\sim 40 \mathrm{~km}$ may be adequate to resolve folds well.) The peak between $39^{\circ} \mathrm{N}$ and $42^{\circ} \mathrm{N}$ appears to be due not only to the low-level PV but also to the PV maxima at other levels. In the higher-resolution model, the peak near $43.5^{\circ} \mathrm{N}$ now appears to be associated with a pocket of high PV located at $200 \mathrm{hPa}$. The PV maximum at this level is part of the tube-like feature extending from the west in track $b$.

\section{Conclusions}

Trajectory and total ozone analyses for the severe weather event of April 8, 1999, detail complex cyclone structure. Stratospheric air was found to play a direct role in damaging surface winds that occurred well to the southwest of intense convec-

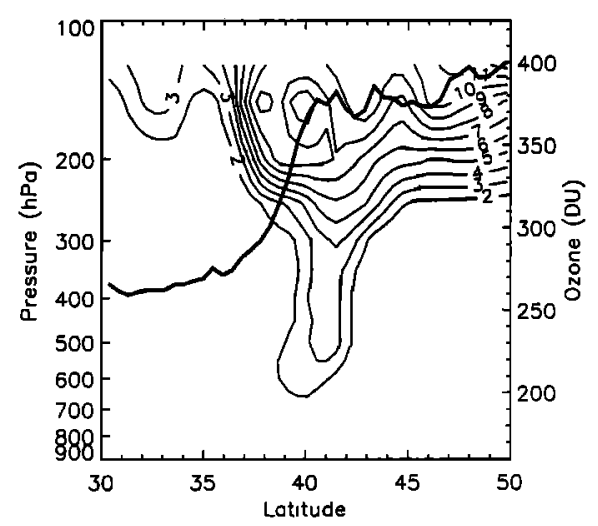

Figure 4. Vertical cross section of potential vorticity from 1800 UTC RUC analysis along-track e (denoted by black line in Plate 5a) from $30^{\circ} \mathrm{N}$ to $50^{\circ} \mathrm{N}$. Total ozone (thick solid line) overlaid. Contours of potential vorticity start at 2 PVU with intervals of 1 PVU. The scale of total column ozone is shown in DU on the right. Pressure is shown on the left. 

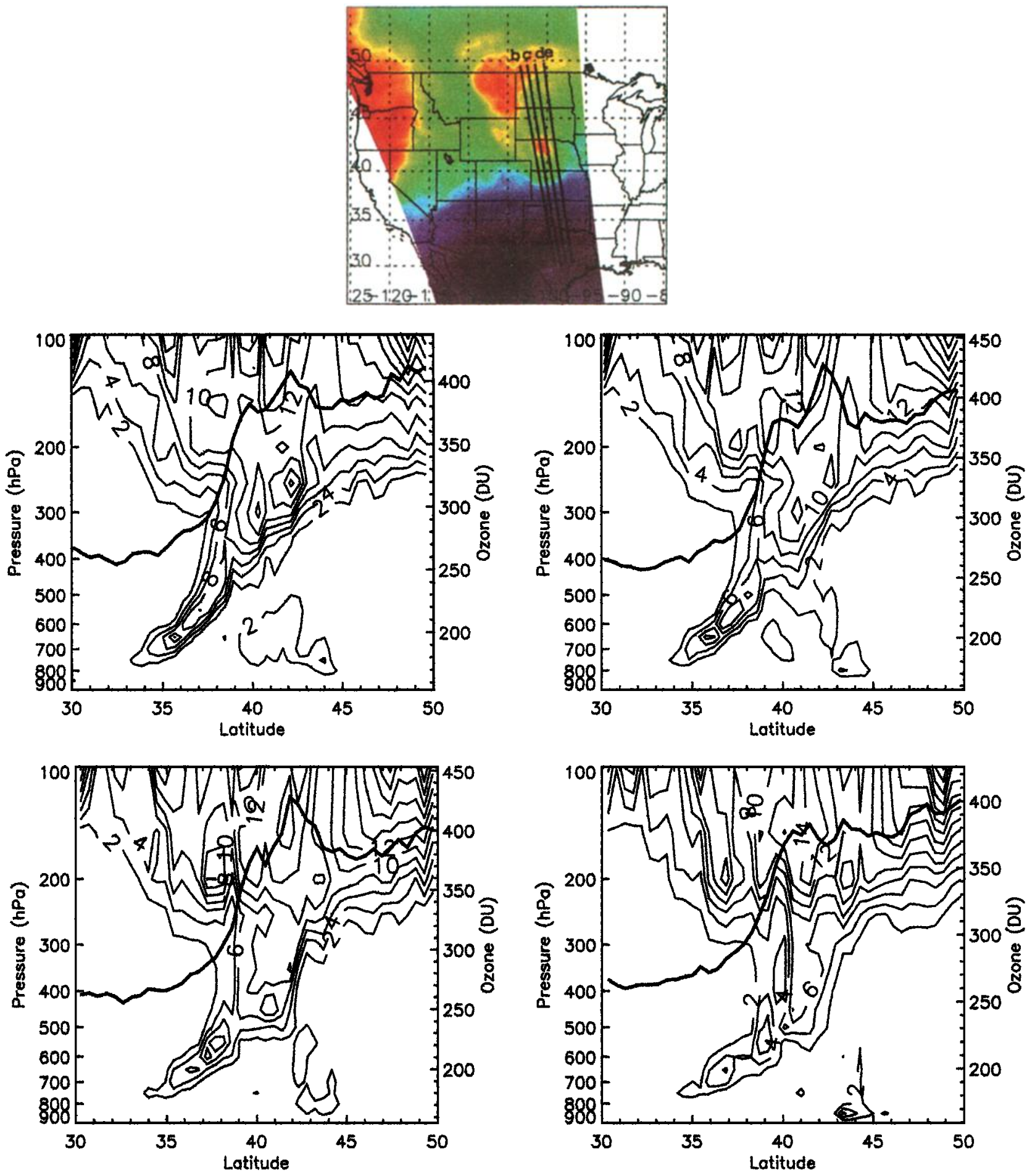

Plate 5. EP/TOMS total ozone on April 8, 1999, shown in panel a with solid black lines denoting the tracks for the corresponding cross-sections b-e. Vertical cross sections of potential vorticity from the $40 \mathrm{~km}$ Eta model valid at 1800 UTC are shown in cross-sections b-e. Total ozone (black solid line) is overlaid with measurements in DU scaled in right-hand vertical axis. Contours of potential vorticity start at 2 PVU with intervals of 2 PVU.

tion. An examination of PV in parcel trajectories in parts of northeast Kansas and the Texas-Oklahoma panhandle region showed that stratospheric air descended to below $700 \mathrm{hPa}$ in these areas around the time damaging winds were reported. The development of the daytime convective boundary layer facilitated mixing the rapidly moving stratospheric air down- ward to the surface. These findings are similar to Browning and Reynolds [1994] who proposed a method for forecasting damaging surface winds by predicting the descending PV at the 2 $\mathrm{km}$ level.

Although stratospheric air descends as low as $800 \mathrm{hPa}$ in this case, the descent occurs southwest of the region of convective 
initiation, and ozone-rich air (implied by high PV) is not apparent at low-middle levels in the immediate vicinity of the convection at 1800 UTC. Trajectories show that the descending dry air is a combination of stratospheric and upper tropospheric air. The region of stratospheric descent, shown in the trajectories, matches fairly well with the region of higher bands of total ozone. Stratospheric air, present at $800 \mathrm{hPa}$ over the Texas panhandle, marked the southernmost extent of the tropopause fold. Trajectories southeast of the total ozone maximum showed descending stratospheric air and ascending tropospheric air converging at midlevels near $700 \mathrm{hPa}$.

The dry air near the convection around OFK, SUX, and OMA was thus a combination of descending upper tropospheric air and ascending lower tropospheric air from arid regions to the southwest. Because stratospheric air did descend to levels around $700 \mathrm{hPa}$ within $150-200 \mathrm{~km}$ southwest of the severe thunderstorms, and trajectory analyses can have spatial errors due to inadequate model resolution, it is possible that stratospheric air may have been entrained within tropospheric air in the vicinity of the storms. However, model output did not suggest speed errors in the simulated movement of the cyclone, and the general agreement of both isentropic and full 3-D wind-based trajectories with the PV evolution suggests that any errors were not large.

The total ozone data may provide a way to verify models and to assist in determining the origin of air parcels. In this study, a RUC analysis demonstrated the capability of total ozone data to capture the detailed structure of mesoscale features. The total ozone also aided in determining whether PV was of stratospheric origin or if it was diabatically generated in the troposphere.

Many authors have discussed the possible use of total ozone as a forecasting tool, and methods of assimilating some types of ozone data (discussed by Ravetta et al. [1999]) are being tested at some operational forecasting centers. Shapiro et al. [1982] proposed that ozone could be used in nowcasting the upper tropospheric flow location and intensity. Davis et al. [1999] developed a technique using total ozone data to derive a threedimensional PV field that can supply thermal and velocity data via the invertibility principle [Hoskins et al., 1985]. Demirtas and Thorpe [1999] compared water vapor images to modeled PV fields and identified mismatched regions. They adjusted the PV field based on water vapor images and showed that the short-range forecast could be improved. Although they used water vapor data, a similar technique could be considered using total ozone data. In this case, for instance, the RUC analysis and Eta forecast had a small southward bias in the location of the cyclone. The spatial error was small enough that it might normally have little impact on a forecast, but in a severe weather outbreak situation, where the most violent storms often are concentrated near the warm front, the small error could be important. Total ozone data might allow adjustments in the model initialization. Successive operational RUC model runs throughout the event studied here (12 hour forecasts issued every 3 hours) progressively shifted the system northward in an apparent attempt to correct the southward error. The analysis and forecast errors were evident in the total ozone data and may have improved the forecasting of high and moderate risk regions for severe weather in this case. Additional research is needed to apply the technique using highresolution total ozone data. A problem with current TOMS total ozone data is that the polar orbiting satellite configuration allows observations of a given region only once per day, near local noon. A geosynchronous TOMS would obviate this restriction and allow application of high-resolution total ozone data to short-range forecasting, such as described by Demirtas and Thorpe [1999].

Acknowledgments. The authors would like to thank Jerry Ziemke and colleagues at the NASA Goddard Space Flight Center for providing the EP/TOMS Level 2 total ozone data, the University Corporation for Atmospheric Research UNIDATA program for providing the RUC data, and the Space Science and Engineering Center at Wisconsin for providing the GOES-8 satellite images. The constructive comments of three anonymous reviewers improved the work. This work is supported by NASA grant NAG5-7271.

\section{References}

Allaart, M. A. F., H. Kelder, and L. C. Heijboer, On the relation between ozone and potential vorticity, Geophys. Res. Lett., 20, 811814, 1993.

Appenzeller, C., and H. C. Davies, Structure of stratospheric intrusions into the troposphere, Nature, 358, 570-572, 1992.

Appenzeller, C., H. C. Davies, and W. A. Norton, Fragmentation of stratospheric intrusions, J. Geophys. Res., 101, 1435-1456, 1996.

Benjamin, S. G., K. J. Brundage, and L. L. Morone, The rapid update cycle, part I, Analysis/model description, Tech. Procedures Bull. 416, 16 pp., Natl. Oceanic and Atmos. Admin./Natl. Weather Serv., Washington, D. C., 1994.

Bithell, M., L. J. Gray, and B. D. Cox, A three-dimensional view of the evolution of midlatitude stratospheric intrusions, J. Atmos. Sci., 156, 673-688, 1999.

Bithell, M., G. Vaughan, and L. J. Gray, Persistence of stratospheric ozone layers in the troposphere, Atmos. Environ., 34(16), 2563-2570, 2000.

Browning, K. A., and $\bullet$. Reynolds, Diagnostic study of a narrow coldfrontal rainband and severe winds associated with a stratospheric intrusion, Q. J. R. Meteorol. Soc., 120, 235-257, 1994.

Carlson, T. N., R. A. Anthes, M. Schwartz, S. G. Benjamin, and D. G. Baldwin, Analysis and prediction of severe storms environment, Bull. Am. Meteorol. Soc., 61, 1018-1032, 1980.

Danielsen, E. F., Stratospheric-tropospheric exchange based on radioactivity, ozone, and potential vorticity, J. Atmos. Sci., 25, 502-518, 1968.

Davis, C. A., S. Low-Nam, M. A. Shapiro, X. Zhou, and A. J. Krueger, Direct retrieval of wind from the Total Ozone Mapping Spectrometer (TOMS) data: Examples from FASTEX, Q.J.R. Meteorol. Soc., 125, 3375-3391, 1999.

Demirtas, M., and A. J. Thorpe, Sensitivity of short-range weather forecasts to local potential vorticity modifications, Mon. Weather Rev., 127, 922-939, 1999.

Ertel, H., Ein Heuer hydrodynamischer Wirbelsatz, Meteorol. Z., 159, 271-281, 1942.

Griffiths, M., A. J. Thorpe, and K. A. Browning, Convective destabilization by a tropopause fold diagnosed using potential-vorticity inversion, Q. J. R. Meteorol. Soc., 126, 125-144, 2000.

Hoerling, M. P., T. K. Shaack, and A. J. Lenzen, A global analysis of stratospheric-tropospheric exchange during northern winter, Mon. Weather Rev., 121, 162-172, 1993.

Hoskins, B. J., M. E. McIntyre, and A. W. Robertson, On the use and significance of isentropic potential vorticity maps, Q.J. R. Meteorol. Soc., 111, 877-946, 1985.

Hsu, N. C., R. D. McPeters, C. J. Seftor, and A. M. Thompson, The effect of an improved cloud climatology on TOMS total ozone retrieval, J. Geophys. Res., 102, 4247-4255, 1997.

Janjic, Z. I., The step-mountain Eta coordinate model: Further developments of the convection, viscous sublayer, and turbulence closure schemes, Mon. Weather Rev., 122, 927-945, 1994.

Kleinschmidt, E., Uber Aufbau und Entstehung von Zyklonen, part 3, Meteorol. Rundsch., 4, 89-96, 1951.

Koch, S. E., and P. J. Kocin, Frontal contraction processes leading to the formation of an intense narrow rainband, Meteorol. Atmos. Phys., 46, 123-154, 1991.

Lamarque, J., and P. G. Hess, Cross-tropopause mass exchange and potential vorticity budget in a simulated tropopause folding, $J$. Atmos. Sci., 51, 2246-2269, 1994. 
Langford, A. O., C. D. Masters, M. H. Proffitt, E. Y. Hsie, and A. F. Tuck, Ozone measurements in a tropopause fold associated with a cut-off low system, Geophys. Res. Lett., 23(18), 2501-2504, 1996.

McPeters, R., et al., Earth probe total ozone mapping spectrometer (TOMS) data product user's guide, NASA Tech. Publ. 1998-206895, 1998.

National Climatic Data Center (NCDC), Storm data: February 1999, http://www.ncdc.noaa.gov/pdfs/sd/sd.htm, Natl. Clim. Data Cent., Asheville, N. C., 1999.

Olsen, M. A., W. A. Gallus Jr., J. L. Stanford, and J. M. Brown, Fine-scale comparison of TOMS total ozone data with model analysis on an intense midwestern cyclone, J. Geophys. Res., 105, 20,48720,495, 2000.

Palmen, E., and C. W. Newton, Atmospheric Circulation Systems, 603 pp., Academic, San Diego, Calif., 1969.

Ravetta, F., G. Ancellet, J. Kowol-Santen, R. Wilson, and D. Nedeljkovic, Ozone, temperature and wind field measurements in a tropopause fold: Comparison with a mesoscale model simulation, Mon. Weather Rev., 127, 2641-2653, 1999.

Reed, R. J., A study of a characteristic type of upper-level frontogenesis, J. Meteorol., 12, 226-237, 1955.

Reed, R. J., and E. F. Danielsen, Fronts in the vicinity of the tropopause, Arch. Meteorol. Geophys. Biokllim., A11, 1-17, 1959.

Reed, R. J., and F. Sanders, An investigation of the development of a mid-tropospheric frontal zone and its associated vorticity field, $J$. Meteorol., 10, 338-349, 1953.

Sanders, F., and J. R. Gyakum, Synoptic-dynamic climatology of the "bomb," Mon. Weather Rev., 108, 1589-1606, 1980.

Shapiro, M. A., and D. Keyser, Fronts, jet streams and the tropopause, in Extratropical Cyclones: The Erik Palmen Memorial Volume, edited by C. W. Newton and E. O. Holopainen, pp. 167-191, Am. Meteorol. Soc., Boston, Mass., 1990.

Shapiro, M. A., A. J. Krueger, and P. J. Kennedy, Nowcasting the position and intensity of jet streams using a satellite-borne total ozone mapping spectrometer, in Nowcasting, edited by K. Browning, pp. 137-145, 1982.

Spaete, P., D. R. Johnson, and T. K. Shaack, Stratospherictropospheric mass exchange during the Presidents' Day storm, Mon. Weather Rev., 122, 424-439, 1994.

Stanford, J. L., and J. R. Ziemke, A practical method for predicting midlatitude total column ozone form operational forecast temperature fields, J. Geophys. Res., 101, 28,769-28,774, 1996.

Thorncroft, C. D., B. J. Hoskins, and M. E. McIntyre, Two paradigms of baroclinic-wave life-cycle behavior, Q.J. R Meteorol. Soc., 119, 17-55, 1993.

Uccellini, L. W., D. Keyser, K. Brill, and C. H. Wash, The Presidents' Day cyclone of 18-19 February 1979: Influence of upstream trough amplification and associated tropopause folding on rapid cyclogenesis, Mon. Weather Rev., 113, 962-988, 1985.

Vaughan, G., and D. A. Begun, Correlation between total ozone and potential vorticity, in Ozone in the Atmosphere, edited by Rumen D. Bojkov and Peter Fabian, pp. 91-94, Góttingen, Germany, 1989.

World Meteorological Organization (WMO), Atmospheric ozone 1985, WMO Rep. 16, 392 pp., Global Ozone Res. and Monit. Rep., Geneva, Switzerland, 1986.

Ziemke, J. R., and J. L. Stanford, Kelvin waves in total column ozone, J. Geophys. Res. Lett., 21, 105-108, 1994.

W. A. Gallus Jr. and M. A. Goering, Department of Geological and Atmospheric Sciences, 3025 Agronomy, Iowa State University, Ames, IA 50011. (wgallus@iastate.edu)

M. A. Olsen and J. L. Stanford, Department of Physics and Astronomy, Iowa State University, Ames, IA 50011.

(Received June 8, 2000; revised September 25, 2000; accepted September 27, 2000.) 